\title{
Pelatihan Pemanfaatan Limbah Padi Menjadi Arang Sekam untuk Menambah Pendapatan Petani
}

\section{(Training on the Utilization of Rice Waste into Husk Charcoal to Increase Farmers' Income)}

\author{
Filda Rahmiati*, Grace Amin, Emilius German \\ Program Studi Manajemen, Fakultas Bisnis, Universitas Presiden, Jalan Ki Hajar Dewantara, \\ Jababeka Education Park, Cikarang, Bekasi 17550. \\ *Penulis Korespondensi: filda.rahmiati@president.ac.id \\ Diterima Oktober 2018/Disetujui April 2019
}

\begin{abstract}
ABSTRAK
Salah satu upaya untuk menambah pendapatan para petani adalah dengan mengolah kembali limbah padi menjadi sesuatu yang memiliki nilai jual seperti dibuat arang sekam. Arang sekam memiliki banyak manfaat baik di dunia pertanian maupun untuk kebutuhan industri. Pemanfaatan limbah padi masih terbatas saat ini, sehingga disaat musim panen limbah padi yang melimpah dapat mencemari lingkungan terutama di saat panen pada musim penghujan. Tujuan kegiatan Pengabdian Kepada Masyarakat (PKM) ini adalah memberikan solusi dengan mengadakan pelatihan cara pembuatan arang sekam dari limbah padi secara sederhana. Peserta kegiatan PKM ini adalah para petani di Desa Sukamaju, Kecamatan Tambelang, Kabupaten Bekasi. Kegiatan yang dilakukan adalah dengan mensosialisasikan manfaat serta cara membuat arang sekam kepada para petani. Pada petani diberikan contoh alat sederhana untuk proses pembakaran padi menjadi arang sekam dan di perlihatkan secara langsung cara kerjanya sampai pada proses pengemasan hingga siap untuk dijual. Petani di Desa Sukamaju diharapkan mampu memanfaatkan limbah padi menjadi sesuatu yang bernilai jual, sehingga diharapkan dapat memberikan keuntungan dari segi ekonomi, produktivitas tanaman, maupun dari segi pelestarian lingkungan.
\end{abstract}

Kata kunci: limbah, lingkungan, nilai jual, pertanian

\begin{abstract}
One of the efforts to increase paddy farmers' income is to reprocess the rice hull into husk charcoal which has many benefits both for agriculture and industry. The utilization of rice hull is still limited nowadays. For example, when the harvest is abundant, the husk pollute the environment especially during harvest in the rainy season. The main purpose of this community service activity is to conduct training on how to produce husk charcoal from rice hull. The participants were paddy farmers at Sukamaju Village, Tambelang Subdistrict, Bekasi District. The activities carried out were to socialize the benefits of husk charcoal and how to make husk charcoal from rice hull. The farmers were given simple tools for the process of burning rice hull into husk charcoal and were demonstrated directly how it works until the packaging process which is ready for sale. After the training, the farmers at Sukamaju Village, are expected to be able to recycle rice hull into something which has value for sale resulting in benefits in terms of economy, crop productivity, and environmental preservation.
\end{abstract}

Keywords: agriculture, environment, rice hull, sale value

\section{PENDAHULUAN}

Padi adalah makanan pokok masyarakat Indonesia, maka dari itu melimpahnya produksi padi membawa kesejahteraan bagi manusia. Akan tetapi dengan berlimpahnya produksi padi, limbah yang dihasilkan juga melimpah. Menurut Utomo \& Yunita (2014), hampir semua sekam padi yang diproduksi di negara ASEAN dibuang atau terbuang begitu saja. Masih sedikit pemanfaatan yang dilakukan untuk mengurangi dampak lingkungan yang dihasilkan dari limbah sekam padi. Limbah pertanian apabila diproses secara alami berlangsung lambat sehingga menjadi penyebab pencemaran lingkungan juga pada kesehatan manusia. Maka dari itu pemanfaatan limbah pertanian sangatlah penting. (Patabang 2012; Santo et al. 2010) bahkan Karyaningsih (2012) menyimpulkan pemanfaatan limbah pertanian ini berdampak dari segi energi, finansial, dan ekologi. 
Energi alternatif dapat dihasilkan dari pemanfaatan limbah pertanian seperti dari sekam padi dengan menggunakan teknologi tepat guna yang sederhana dan sesuai untuk daerah pedesaan (Apriani 2015) Pemanfaatan limbah padi seperti sekam dapat diambil energinya sebagai bahan alternatif pengganti bahan bakar yang bermanfaat untuk kebutuhan manusia. (Santo et al. 2010). Baderan \& Hamidun (2016) menambahkan pengolahan limbah untuk energi memberikan peluang kepada bisnis, kepada lingkungan, dan bagi pembangunan pedesaan. Limbah/residu pertanian tersebut selanjutnya digunakan sebagai bahan baku/sumber energi biomassa. Residu pertanian dapat diolah menjadi bahan bakar cair atau termokimia untuk menghasilkan listrik dan panas (Suhermanto 2014).

Pemanfaatan arang sekam tidak hanya sebagai sumber energi bahan bakar tetapi arangnya juga dapat dijadikan sebagai bahan pembenah tanah (perbaikan sifat-sifat tanah) dalam upaya rehabilitasi lahan dan memperbaiki partumbuhan tanaman. Arang sekam juga dapat menambah hara tanah walaupun dalam jumlah sedikit. Oleh karena itu, pemanfaatan arang sekam menjadi sangat penting dengan banyaknya tanah terbuka/lahan marginal akibat degradasi lahan yang hanya menyisakan subsoil (tanah kurus) (Supriyanto \& Fiona 2010) juga dapat memperbaiki kualitas lahan pertanian dengan meningkatkan kandungan $\mathrm{C}$ organik tanah dan peningkatan produktivitas padi (Karyaningsih 2012). Penambahan arang sekam sebagai campuran media tanam atau saat olah lahan pertanian juga memiliki kontribusi besar bagi tanaman (Kartika 2016). Arang sekam juga sangat baik jika ditambahkan sebagai campuran untuk media persemaian, karena kandungan unsur silikat (Si) terbukti resisten terhadap serangan hama dan patogen tanah.

Pada proses penggilingan beras, sekam akan terpisah dari butir beras dan menjadi limbah penggilingan. Sekam padi dikategorikan sebagai biomassa. Dari proses penggilingan padi biasanya diperoleh sekam berkisar 20-30\%, dedak berkisar 8-15\% dan beras giling berkisar 50-63,5\% data bobot awal gabah (Patabang 2012). Limbah yang berasal dari pengolahan hasil pertanian secara umum memiliki kandungan gizi yang tinggi, dan tingginya kandungan pati yang menghasilkan senyawa yang dapat merangsang pertumbuhan tanaman (Irianto 2015). Pada saat ini kebanyakan limbah sekam yang berlimpah dimanfaatkan dengan melakukan penimbunan lahan sawah yang ada di sekitar pabrik penggilingan yang tujuan sementara mengurangi tumpukan jumlah limbah yang ada di pabrik penggilingan. Ada juga dengan menjual dengan harga yang sangat rendah dan memerlukan biaya pengangkutan yang cukup besar (Abdullahi \& Mustaka 2016). Hal ini sangat tidak ekonomis. Maka diperlukan pemanfaatan sekam padi agar lebih bernilai jual.

Apabila lebih lanjut di proses sekam padi dapat dijadikan produk yang bermanfaat. Arang sekam dapat diproses menjadi briket arang sekam yang memiliki manfaat yang lebih sebagai bahan bakar ramah lingkungan, media tanaman, dan tumbuhan khususnya tanaman bunga (Santo et al. 2010) juga sebagai pakan ternak inkovensional karena kandungan gizi yang bervariasi (Agustono et al. 2017). Dilihat dari komposisi kimiawi yang terkandung pada sekam padi, sekam padi dapat dimanfaatkan untuk berbagai keperluan seperti bahan baku pada industri kimia, bahan bangunan seperti semen, dan sebagai sumber energi panas untuk keperluan manusia (Sugiarti \& Widyatama 2009).

Berdasarkan pembahasan tersebut, pemanfaatan arang sekam masih terbatas. Besarnya pemanfaataan limbah padi menjadi arang sekam belum banyak yang mengetahui. Maka dari itu kegiatan PKM ini dilakukan untuk memberikan pengetahuan tentang pemanfaatan dari arang sekam, bagaimana mengubah limbah kulit padi menjadi arang sekam yang mempunyai nilai jual yang diharapkan dapat memberikan penghasilan tambahan bagi para petani di lingkungan Desa Sukamaju, Kecamatan Tambelang, Kabupaten Bekasi.

Tujuan dari kegiatan pengabdian kepada masyarakat (PKM) ini adalah untuk memperkenalkan dan memberi pengetahuan tambahan kepada mitra dalam pengelolaan pemanfaatan limbah sekam padi sebagi solusi dalam membuat produk yang bernilai jual untuk menambah penghasilan petani. Pendekatan yang dilakukan dengan cara memberikan penyuluhan partisipatif dan pelatihan dalam pengolahan limbah sekam padi menjadi arang sekam.

\section{METODE PELAKSANAAN KEGIATAN}

Metode yang digunakan dalam kegiatan PKM ini adalah lebih kepada cara penyuluhan partisipatif dan pelatihan (Sulmiyati \& Said 2017). Penyuluhan partisipatif dilakukan dengan memberikan penyuluhan secara verbal maupun visual, pelatihan dilakukan dengan memberikan 
pelatihan pengolahan arang sekam secara langsung sampai proses pengemasan untuk siap dijual di pasar. Hal ini dilakukan agar peserta dapat langsung melaksanakan praktik sehingga mereka dapat lebih mudah untuk menguasai materi yang akan diberikan.

Mitra dalam kegiatan PKM ini adalah para petani sejumlah 7 orang yang berdomisili di Desa Sukamaju, Kecamatan Tambelang, Kabupaten Bekasi sebagai peserta pelatihan yang menerima materi penyuluhan dan pembimbingan. Tahap pelaksanaan penyuluhan meliputi pengetahuan cara membuat alat sederhana untuk proses pembakaran arang sekam, proses pembakaran arang sekam, serta pengemasan dan pemasaran arang sekam.

\section{Alat dan Bahan}

Alat-alat yang dibutuhkan pun mudah didapatkan seperti sekam padi, alat pembakaran (untuk alat pembakaran menggunakan kaleng bekas ataupun kawat yang dibentuk seperti tabung), koran atau kertas bekas, korek api, minyak tanah, arang, air dan tempat untuk menampung air, sekop, dan wadah penyimpanan pupuk yang sudah jadi (karung atau plastik).

\section{Tahap Persiapan dan Penentuan Target Kelompok Sasaran}

Lokasi pelatihan pemanfaatan sekam padi dilakukan di Desa Sukamaju, Kecamatan Tambelang, Kabupaten Bekasi yang masih banyak lahan pertanian seperti persawahan. Mitra kegiatan PKM ialah kelompok tani di salah satu penggilingan padi. Jumlah peserta saat itu berjumlah 7 orang dan diharapkan dapat membantu menyebarkan informasi kepada para petani lainnya. Gambar 1 menunjukkan dari satu tempat penggilingan padi sudah sangat banyak sekam yang dihasilkan dari proses penggilingan dan itu sangat mengganggu lingkungan terutama saat musim hujan tiba. Selama ini, yang dilakukan hanya menjual kepada pemasok dengan harga yang sangat rendah setidaknya dapat mengurangi dampak lingkungan yang ditimbulkan. Maka dari itu pemanfaatan limbah sekam sangat di perlukan untuk mengatasi permasalahan yang ada dan diharapkan dapat memberikan pendapatan tambahan bagi para petani.

\section{Tahapan Penyuluhan Pembuatan Arang Sekam}

\section{- Membuat alat pembakaran}

Pembuatan arang sekam dari limbah padi ini cukup sederhana dan mudah. Metode yang digunakan saat pelatihan masih tradisional. Pembuatan alat pembakaran bisa menggunakan kaleng bekas berukuran agak besar yang sisisisinya dilubangi. Selain itu, juga bisa memanfaatkan rangkaian kawat yang dibentuk menjadi seperti tabung. Pada kegiatan ini tim memanfaatkan rangkaian kawat yang dibentuk menyerupai tabung sebagai alat pembakaran. Hal ini dimaksudkan agar lidah api menjulur keluar, karena apabila bagian yang tajamnya mengarah ke dalam lidah api tidak akan menjulur keluar seperti pada Gambar 2.

\section{- Proses pembakaran arang}

Pemilihan lokasi pembakaran yang jauh dari perumahan atau jalan, karena proses pembakaran sekam padi akan menimbulkan asap yang tebal. Sebaiknya alas tempat pembakaran terbuat dari lantai keras yang tahan panas, atau alasi bagian bawah dengan plat seng sebelum melakukan pembakaran. Hal ini untuk memudahkan pengambilan arang sekam. Tetapi saat melakukan percobaan tersebut langsung di atas tanah dapat dilihat pada Gambar 3.

Buat gundukan/tumpukan sekam mengelilingi pipa pembakaran dimana pipa tersebut

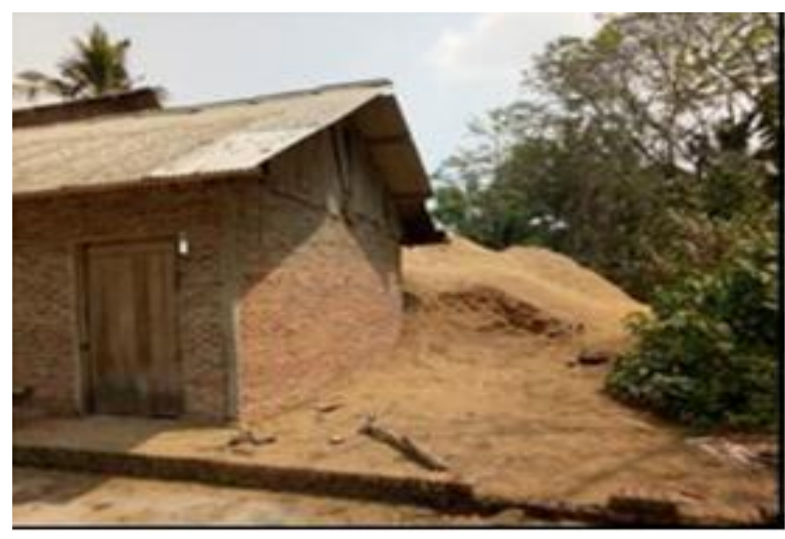

Gambar 1 Limbah sekam padi saat panen.

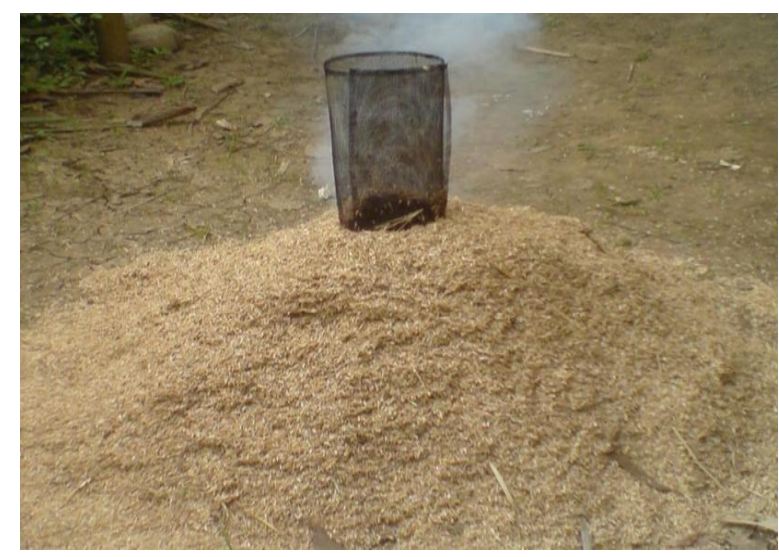

Gambar 2 Alat Pembakaran Arang Sekam 
tepat berdiri tegak dan berada di tengah-tengah gundukan sekam (Vachlepi \& Suwardin 2013). Masukkan beberapa bungkus arang ke dalam pipa pembakaran tadi, beri sedikit minyak tanah untuk memudahkan proses pembakaran kemudian nyalakan api dengan menggunakan kertas bekas ataupun koran bekas. Setelah 20-30 menit atau saat puncak timbunan sekam padi terlihat menghitam, naikkan sekam yang masih berwarna cokelat di bawah ke arah puncak. Lakukan terus sampai semua sekam padi menghitam sempurna.

Setelah semua sekam berubah menjadi hitam, siram dengan air hingga merata. Penyiraman dilakukan untuk menghentikan proses pembakaran. Apabila proses pembakaran tidak dihentikan maka arang sekam akan berubah menjadi abu. Setelah disiram dan suhunya menurun, bongkar gunungan arang sekam dan keringkan. Kemudian masukkan ke dalam karung dan simpan di tempat kering.

Penyuluhan partisipatif dan pelatihan (demonstrasi) dilakukan dengan memberikan pelatihan kepada para peserta dibimbing mulai dari teori (Gambar 4), melihat cara pembuatan langsung arang sekam, dan kemudian mulai belajar langsung langkah demi langkah pembuatan arang sekam sampai jadi hingga cara pengemasannya.

\section{HASIL DAN PEMBAHASAN}

Pelatihan pembuatan arang sekam sangat menarik perhatian masyarakat di Desa Sukamaju karena hal ini merupakan suatu pengalaman baru bagi mereka. Selama ini limbah padi tersebut hanya menjadi sampah yang tidak bernilai jual karena masyarakat kurang paham cara memanfaatkannya. Setelah mendengar penjelasan mengenai manfaat arang sekam masyarakat mulai memahami kegunaan jangka panjang dari pengetahuan ini. Mereka akhirnya sadar akan keuntungan yang bisa mereka dapatkan dari hasil pemanfaatan dan penjualan arang sekam.

Masyarakat terlihat antusias memerhatikan paparan penyuluh mengenai alat yang dibutuhkan serta cara pembuatan arang sekam. Selama pelatihan berlangsung, beberapa orang peserta pelatihan secara aktif mengajukan pertanyaan terkait proses pembuatan arang sekam. Para peserta juga berkesempatan untuk mempraktikkan secara langsung bagaimana cara membuat alat pembakaran sederhana dari kaleng bekas atau kawat yang dibuat seperti tabung dengan tambahan minyak tanah, kertas,

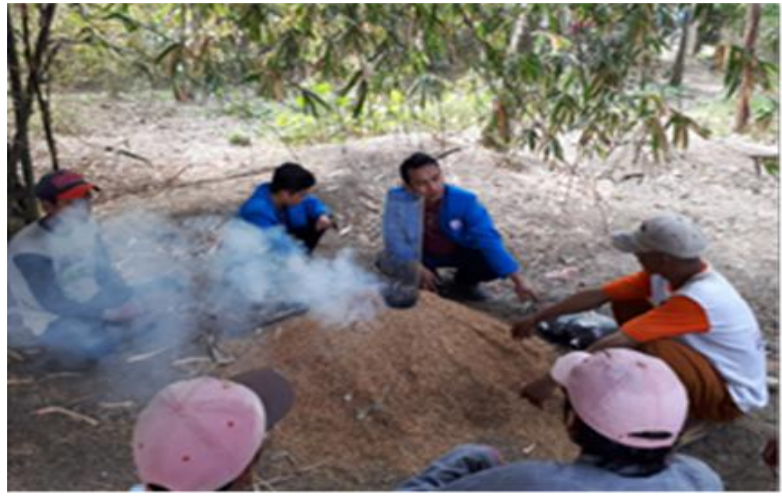

Gambar 3 Proses pembakaran sekam.

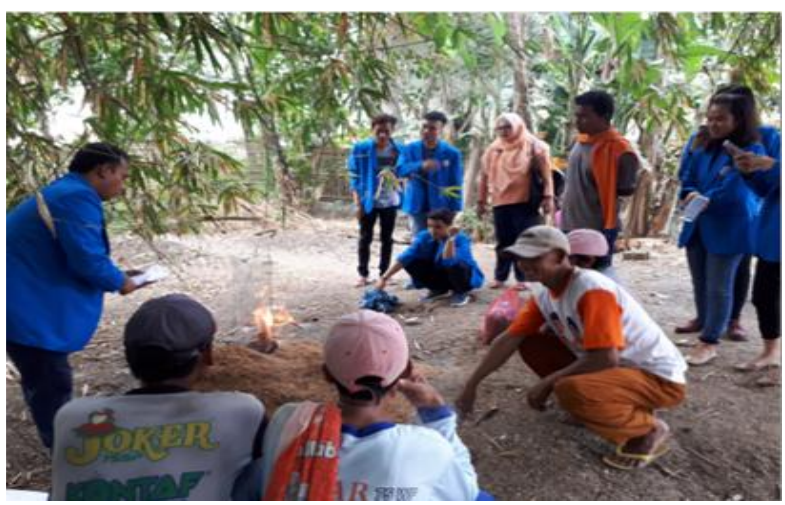

Gambar 4 Pemaparan teori mengenai arang sekam.

serta korek api. Pemberian kesempatan praktik secara langsung kepada masyarakat diharapkan di kemudian hari masyarakat Desa Sukamaju dapat melakukan proses pembuatan arang sekam ini secara mandiri.

Ketujuh peserta pelatihan memahami cara membuat arang sekam. Peserta juga tertarik untuk melanjutkan usaha pembuatan arang sekam secara mandiri. Musim panen terjadi hanya beberapa bulan dalam setahun, maka waktu luang para petani saat tidak ada panen dan dengan ketersediaan sekam yang cukup banyak bisa dimanfaatkan untuk pendapatan lebih para petani.

Setelah mendapatkan pembekalan mengenai cara pembuatan arang sekam, peserta juga diberikan pelatihan tentang cara menjual produk arang sekam yang telah mereka hasilkan, salah satunya menggunakan media online seperti di aplikasi Tokopedia atau aplikasi penjualan online lainnya seperti terlihat pada Gambar 5. Penyuluh mencoba menunjukkan peningkatan harga jual arang sekam yang telah dijual dibandingkan dengan arang kayu yang belum diolah karena arang sekam dapat digunakan bagi kebutuhan industri seperti peleburan biji baja, holtikultura, media tumbuh tanaman, bahan bakar ramah 


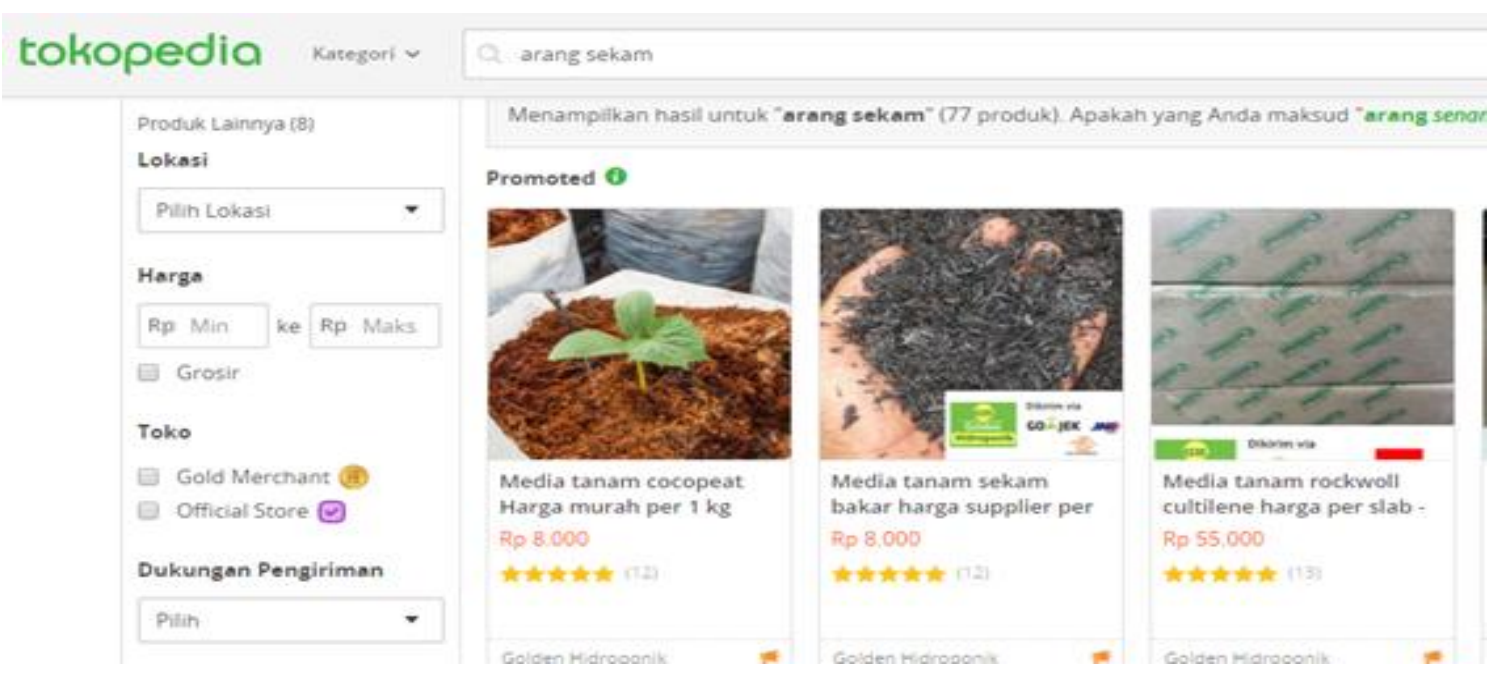

Gambar 5 Cara pemasaran arang sekam secara online.

lingkungan, serta kebutuhan rumah tangga. Arang kayu yang belum diolah dengan benar harganya sebesar Rp 1000-1500/kg. Harga ini berbeda jauh dengan harga arang sekam yang telah diolah, yaitu Rp 7000-7500/kg. Peserta penyuluhan semakin terlihat antusias ketika mereka mengetahui keuntungan tambahan yang akan mereka peroleh dari pengolahan arang tersebut. Mereka merasa hal ini dapat meningkatkan pendapatan dan perekonomian.

Dalam melakukan program ini, banyak manfaat yang dirasakan sehingga keberlanjutan program ini sangat dibutuhkan. Penyuluh berharap kegiatan ini tidak hanya berlangsung di lumbung padi Desa Sukamaju tetapi juga di lumbung padi lainnya. Walaupun banyak dampak positif dari program ini, penyuluh juga menghadapi beberapa kendala yang perlu dipertimbangkan terkait lokasi yang cukup jauh serta pemilihan waktu yang tepat untuk bertemu dengan para petani karena cukup sulit mengumpulkan para petani yang sibuk bertani untuk tindak lanjut program ini.

\section{SIMPULAN}

Pemanfaatan sekam padi sebagai olahan dari limbah padi diharapkan dapat memberikan penghasilan tambahan bagi masyarakat Desa Sukamaju, Kecamatan Tambelang. Dengan adanya pelatihan pembuatan sekam padi ini, masyarakat mendapatkan pengetahuan lebih sehingga diharapkan dapat memanfaatkan limbah padi yang melimpah untuk diproses menjadi arang sekam. Dengan begitu dapat memberikan pendapatan tambahan, memperbaiki lahan pertanian, dan pelestarian lingkungan.

\section{UCAPAN TERIMA KASIH}

Ucapan terima kasih disampaikan kepada semua pihak yang telah membantu sehingga kegiatan PKM ini dapat selesai dengan baik dan lancar. Terutama kami ucapkan terima kasih kepada Direktur LRPM Universitas Presiden beserta stafnya yang telah mendukung dengan mendanai kegiatan ini, Dekan Fakultas Bisnis, dan Kepala Prodi Manajemen serta kelompok tani Desa Sukamaju, Kecamatan Tambelang yang telah bersedia menjadi mitra kami.

\section{DAFTAR PUSTAKA}

Abdullahi AB, Mustaka ZD. 2016. Penerapan Konsep Zero Waste Pada Usaha Penggilingan Padi di Kabupaten Pinrang. In Seminal Nasional Hasil Penelitian dan Pengabdian kepada Masyarakat (pp. 420-429).

Agustono B, Lamid M, Ma'ruf A, Purnama MTE. 2017. Identifikasi Limbah Pertanian dan Perkebunan Sebagai Bahan Pakan Inkonvensional di Banyuwangi. Jurnal Medik Veteriner. 1(1): 12-22.

Apriani. 2015. Uji Kualitas Biobriket Ampas Tebu Dan Sekam Padi Sebagai Bahan Bakar Alternatif. Makassar (ID): Universitas Islam Negeri (UIN) Alauddin Makassar.

Baderan DW, Hamidun MS. 2016. Pemanfaatan Sekam Padi Sebagai Bahan Bakar Alternatif dan Pupuk Organik Yang Ramah Lingkungan Di Desa Lakeya Kecamatan Tolangohula Kabupaten Gorontalo. KKS Pengabdian. Gorontalo (ID): Universitas Negeri Gorontalo. 
Irianto IK. 2015. Hasil Proses Teknologi Pengolahan Limbah Cair Secara Biologi Terhadap Kualitas dan Produksi Bahan Baku Pupuk. WICAKSANA: Jurnal Lingkungan dan Pembangunan. 24(2): 1-14.

Kartika D. 2016. Peningkatan Ketersediaan Fosfor (P) Dalam Tanah Akibat Penambahan Arang Sekam Padi Dan Analisisnya Secara Spektrofotometri. [Thesis]. Jawa Timur (ID): Universitas Jember.

Karyaningsih S. 2012. Pemanfaatan limbah pertanian untuk mendukung peningkatan kualitas lahan dan produktivitas padi sawah. Buana Sains. 12(2): 45-52.

Patabang D. 2012. Karakteristik Termal Briket Arang Sekam Padi dengan Variasi Bahan Perekat. Jurnal Mekanikal. 3(2): 286-292.

Santo RF, Nuraeni S, Rochiyat. 2010. Potensi Sekam Sebagai Bahan Alternatif yang Dapat Dipakai Berulang-ulang. Bogor (ID): Institut Pertanian Bogor.

Sugiarti W, Widyatama W. (2009). Pemanfaatan Kulit Biji Mete, Bungkil Jarak, Sekam Padi Dan Jerami Menjadi Bahan Bakar Briket Yang Ramah Lingkungan Dan Dapat Diperbarui. [Skripsi]. Semarang (ID): Universitas
Diponegoro.

Suhermanto H. 2014. Pengelolaan libah/residu pertanian untuk energi: Potensi peran koperasi. Bappenas. 2(XX): 1-20.

Sulmiyati, Said NS. 2017. Pengolahan Briket BioArang Berbahan Dasar Kotoran Kambing dan Cangkang Kemiri di Desa Galung Lombok , Kecamatan Tinambung, Polewali Mandar. Jurnal Pengabdian Kepada Masyarakat. 3(1): 108-117. https://doi.org/10.22146/ jpkm.25529

Supriyanto S, Fiona F. 2010. Utilization of RiceHush Charcoal to Improve Growth of Jabon Seedlings (Anthocephalus cadamba (Roxb.) Miq) on Subsoil Media. Jurnal Silvikultur Tropika. 1(1): 24-28.

Utomo P, Yunita I. 2014. Sintesis Zeolit dari Abu Sekam Padi Pada Temperatur Kamar. Yogyakarta (ID): Universitas Negeri Yogyakarta.

Vachlepi A, Suwardin D. 2013. Penggunaan Biobriket Sebagai Bahan Bakar Alternatif Dalam Pengeringan Karet Alam. Warta Perkaretan. 32(2): 56-73. https://doi.org/ 10.22302/ppk. wp.v32i2.38 